\title{
Precursor influence on the electrical properties of textured Bi-2212
}

\section{superconductors}

\author{
A. Sotelo, Sh. Rasekh, M. A. Madre, J. C. Diez \\ Instituto de Ciencia de Materiales de Aragón (ICMA) (CSIC-Universidad de \\ Zaragoza), C/Mª de Luna, 350018 Zaragoza. Spain
}

Title running head: Precursor influence on Bi-2212 LFZ textured superconductors

\begin{abstract}
Several synthetic methods, solid state, sol-gel and polymer solution method, have been used to prepare prereacted precursors, as well as a vitreous material obtained by melt-quenching. The influence of the starting powder characteristics on the phase formation, microstructure, $\mathrm{T}_{\mathrm{c}}$ and $\mathrm{J}_{\mathrm{c}}$ of $\mathrm{Bi}-2212$ textured rods prepared by directional crystallization from the melt has been analysed. In all the cases, high transport critical current values (higher than $3000 \mathrm{~A} / \mathrm{cm}^{2}$ at $77 \mathrm{~K}$ ) have been obtained, independently of the precursor type. Samples obtained by the polymer route show improved $T_{c}$ values, associated to a lower oxygen content.
\end{abstract}

Keywords: Bi-2212, Resistivity, Critical current, Synthesis, Directional growth.

Corresponding author: A. Sotelo, asotelo@unizar.es; Tel: +34 976762617; Fax: +34 976761957 


\section{INTRODUCTION}

The fabrication of bulk high-Tc superconducting ceramics with well oriented microstructure and being able of carrying high currents below $77 \mathrm{~K}$, is of great interest for the development of practical devices [1]. $\mathrm{Bi}_{2} \mathrm{Sr}_{2} \mathrm{CaCu}_{2} \mathrm{O}_{8+\delta}(\mathrm{Bi}-2212)$ superconductors have demonstrated that they are suitable for many applications when they are properly processed in order to obtain a good grain alignment [2, 3]. Among other techniques which produce well textured materials [4-6], the directional grown from the melt, as the Laser Floating Zone (LFZ) method, has demonstrated to be a useful technique for rapidly growing well textured BSCCO rods [7-9]. As it was reported in previous works [10], the microstructure of the superconducting materials is characterized by a good alignment of the grains, with their $a-b$ planes quasi-parallel to the growth direction. This high degree of texture leads to a very important increase of the transport properties, $J_{c}$, due to the reduction of the number of low-angle junctions [11].

Although in previous works the characteristics of the starting powder have been observed to play an important role towards superconductor phase formation and microstructure development in $\mathrm{Pb}$-substituted, $\mathrm{Bi}-2223$ bulk sintered and textured ceramics [12-14], a similar study has not been performed with Bi-2212 textured ceramics. Furthermore, it is very important to acquire an improved understanding of all the parameters (phase content, morphology and homogeneity of the starting powders) that could affect the solidification process and, as a consequence, phase formation and microstructure of LFZ Bi-2212 processed samples. The control of these parameters would lead to the 
production of textured superconducting ceramics with high $J_{c}$ values together with a high degree of reproducibility.

On the other hand, considering industrial production, it is necessary to have into account the above parameters in order to modify the existing synthetic methods, or designing new ones, which lead to a reduction on the processing time of precursors and/or an improvement in the final properties, compared with the classical solid state method. Some methods have already shown their potential in the reduction of the processing time and/or the improvement of the transport properties on bulk sintered $\mathrm{Bi}-2212$ and $\mathrm{Bi}(\mathrm{Pb})-2223$ ceramics [15-17]. The aim of this work is developing reproducible precursor powder preparation methods that yield optimum quality $\mathrm{Bi}_{2} \mathrm{Sr}_{2} \mathrm{CaCu}_{2} \mathrm{O}_{x}$ textured materials, using the LFZ technique. It is presented a comparison of directionally grown materials from precursors obtained by four different preparation methods, the conventional solid-state synthesis, a sol-gel method, a versatile polymer solution synthesis route developed in our laboratory, and a melt-quenching process.

\section{EXPERIMENTAL}

The initial $\mathrm{Bi}_{2} \mathrm{Sr}_{2} \mathrm{CaCu}_{2} \mathrm{O}_{x}$ materials, used in this work, were prepared by the following methods:

(i) Solid-state reaction: $\mathrm{Bi}_{2} \mathrm{O}_{3}\left(98 \%\right.$, Panreac), $\mathrm{SrCO}_{3}\left(98+\%\right.$, Panreac), $\mathrm{CaCO}_{3}$ (98.5\%, Panreac), and $\mathrm{CuO}$ (98\%, Panreac), were attritor-milled using zirconia balls and absolute ethanol for $1.5 \mathrm{~h}$ at $600 \mathrm{rpm}$. The resulting suspension was dried using IR radiation and subsequently placed in an oven at $200 \stackrel{\circ}{\circ}$ for $24 \mathrm{~h}$ in order to evaporate the maximum amount of ethanol. The resulting mixture 
was placed in a furnace and heated slowly to $750^{\circ} \mathrm{C}$, where it was kept for ca. $12 \mathrm{~h}$, followed by furnace cooling. After cooling, the remaining powder was manually ground and heated again at $800^{\circ} \mathrm{C}$ for $12 \mathrm{~h}$, milled and isostatically pressed at c.a. $200 \mathrm{MPa}$ in form of cylinders $(2-3 \mathrm{~mm}$ diameter and $120 \mathrm{~mm}$ long).

(ii) Sol-gel: $\mathrm{Bi}\left(\mathrm{NO}_{3}\right)_{3} \cdot 5 \mathrm{H}_{2} \mathrm{O}\left(\geq 98 \%\right.$, Aldrich), $\mathrm{SrCO}_{3}\left(98+\%\right.$, Panreac), $\mathrm{CaCO}_{3}$ (98.5\%, Panreac), CuO (98\%, Panreac), were suspended in distilled water. Concentrated $\mathrm{HNO}_{3}$ (analysis grade, Panreac) was added dropwise into the suspension until it turned into a clear blue solution. Citric acid (99.5\%, Panreac), and ethylene glycol (99\%, Panreac), were added to this solution in the adequate proportions. Evaporation of the solvent was performed slowly in order to decompose the nitric acid excess, which allows the polymerization reaction between ethylene glycol and citric acid, forming a blue gel. The dried product was then decomposed (slow self combustion) by heating at $350 \stackrel{\circ}{\mathrm{C}}$ for 1 h. The decomposed solid was mechanically ground and calcined at 750 and $800^{\circ} \mathrm{C}$ for $12 \mathrm{~h}$, with an intermediate grinding. Cylindrical precursors were prepared from these powders by isostatical pressing at about $200 \mathrm{MPa}$ for 1 minute.

(iii) Polymer solution synthesis: To a suspensión of $\mathrm{Bi}\left(\mathrm{CH}_{3} \mathrm{CO}_{2}\right)_{2}(\geq 99.99 \%$, Aldrich), $\mathrm{Sr}\left(\mathrm{CH}_{3} \mathrm{CO}_{2}\right) \cdot 0.5 \mathrm{H}_{2} \mathrm{O}\left(99 \%\right.$, Panreac), $\mathrm{Ca}\left(\mathrm{CH}_{3} \mathrm{CO}_{2}\right) \cdot 2 \mathrm{H}_{2} \mathrm{O}(98 \%$, Alfa Aesar), and $\mathrm{Cu}\left(\mathrm{CH}_{3} \mathrm{CO}_{2}\right)_{2} \cdot \mathrm{H}_{2} \mathrm{O}\left(98 \%\right.$, Panreac) in distilled $\mathrm{H}_{2} \mathrm{O}$, glacial acetic acid (ACS Reagent, Panreac) was added until a light blue clear solution was formed. Polyethylenimine (PEI) (50\% aqueous, Aldrich) was then added to the above solution, which turned darker immediately due to the nitrogen-metal coordination. After partial evaporation ( 80 vol. \%) of water and acetic acid in a 
rotary evaporator, the concentrated solution was placed on a hot plate at $50 \stackrel{\circ}{ } \mathrm{C}$ until a very dark pink thermoplastic paste appeared. Further heating produced a slow combustion with the release of brown fumes (nitrogen oxides). The resulting powder was manually milled and calcined at 750 and $800 \stackrel{\circ}{\mathrm{C}}$ for ca. 12 $\mathrm{h}$, with an intermediate milling, and isostatically pressed at $200 \mathrm{MPa}$ in form of cylindrical bars.

(iv) Melt quenching: $\mathrm{Bi}_{2} \mathrm{O}_{3}\left(98 \%\right.$, Panreac), $\mathrm{SrCO}_{3}\left(98+\%\right.$, Panreac), $\mathrm{CaCO}_{3}$ (98.5\%, Panreac), and CuO (98\%, Panreac), were ball-milled for 30 minutes at $300 \mathrm{rpm}$ and thermally treated at 750 and $800{ }^{\circ} \mathrm{C}$ for $12 \mathrm{~h}$, with an intermediate milling, in order to decompose the carbonates before the melting process. The powder was then placed into a platinum crucible and heated at $1050 \stackrel{\circ}{\mathrm{C}}$ for at least $1 \mathrm{~h}$ in order to homogeneize the melt. The liquid was then introduced in a quartz tube (2 mm internal diameter and $250 \mathrm{~mm}$ length) using a vacuum pump (see Fig. 1), producing a rapid solidification inside the tube which leads to the formation of vitreous cylindrical precursors, as shown in Fig. 2.

The cylinders obtained by the different methods were used as feed in a directional solidification process performed in an LFZ installation [14]. The textured bars were obtained using a continuous power Nd:YAG laser $(\lambda=1064$ $\mathrm{nm}$ ), under air, at a growth rate of $30 \mathrm{~mm} \mathrm{~h}^{-1}$ and a relative rotation of $18 \mathrm{rpm}$ between seed and feed. Using these growth conditions and adjusting the laser power input to obtain a melted zone of $1-1.5$ times the rod diameter, it is possible to obtain stable solidification front, which allows the fabrication of homogeneous textured bars. 
Bi-2212 ceramic presents incongruent melting and, in consequence, after the directional solidification process, it is necessary to perform a thermal treatment in order to form the Bi-2212 superconducting phase $[18,19]$. This annealing process was performed under air, and consisted in two steps: $60 \mathrm{~h}$ at $860^{\circ} \mathrm{C}$, followed by $12 \mathrm{~h}$ at $800{ }^{\circ} \mathrm{C}$ and, finally, quenched in air to room temperature. Before the thermal treatment, silver contacts were painted on the as-grown samples for the electrical measurements. After annealing, the silver contacts have typical resistance values below $1 \mu \Omega$.

Granulometry (CILAS 850 Alcatel Granulometer) measurements were performed throughout the synthetic procedure, using the same conditions for all the samples, to characterize the intermediate products. Samples for granulometric measurements have been prepared by ultrasonic mixing in acetone to insure the breaking of the agglomerates, avoiding their influence on the mean grain size.

Structural identification of all ceramic samples was performed by powder XRD utilizing a Rigaku D/max-B X-ray powder diffractometer (CuKa radiation) with $2 \theta$ ranging between 10 and 60 degrees. Microstructural characterization was performed on polished longitudinal cross-sections of the samples, in a scanning electron microscope (SEM, JEOL JSM 6400) equipped with an energy dispersive spectroscopy (EDX) system.

After annealing, the proportion of the different phases has been estimated from several SEM micrographs using Digital Micrograph software. Annealed samples used for electrical characterization were, approximately, $4 \mathrm{~cm}$ long and were measured using the standard four-probe configuration. Critical current density $\left(J_{c}\right)$ values were determined at $77 \mathrm{~K}$ using the $1 \mu \mathrm{V} / \mathrm{cm}$ criterion. Resistivity as a 
function of temperature, from 77 to $300 \mathrm{~K}$, was measured using a dc current of 1 $\mathrm{mA}$, in order to determine the transport $T_{c}$ values.

Moreover, $J_{c}$ determination at temperatures below $77 \mathrm{~K}$ has been performed by pumping liquid nitrogen in an experimental device described elsewhere [20]. In this work, the results obtained on LFZ textured samples derived from precursors synthesized by four different methods are presented. Precursors S1 are prepared by Solid State reaction, S2 by Sol-Gel, S3 by Polymer Solution, and S4 by Melt-Quenching.

\section{RESULTS AND DISCUSION}

\subsection{Precursors characterization}

Fig. 3 shows the grain size evolution versus thermal treatment time for the solid state, sol-gel and polymer solution synthetic procedures. For all of them, the starting materials have, approximately, the same grain size before calcination. It can also be clearly seen that the grain growth rate is much higher in the polymer solution method than for the other two synthetic methods, which is in agreement with previous studies [21].

A summary of phase analysis results from powder XRD is given in Table I. The final products, with the same nominal composition $\mathrm{Bi}_{2} \mathrm{Sr}_{2} \mathrm{CaCu}_{2} \mathrm{O}_{8}$, are composed, mainly, by the Bi-2212 phase, accompanied by other minor secondary phases, as $\mathrm{Bi}-2201$ and $\mathrm{CaCuO}_{2}, \mathrm{CaCu}_{2} \mathrm{O}_{3}$, or $\mathrm{Ca}_{2} \mathrm{CuO}_{3}$. As expected, XRD studies revealed that sample $\mathrm{S} 1$ was a mixture of all the starting oxides and carbonates before calcination. After calcination at $750{ }^{\circ} \mathrm{C}$ for $12 \mathrm{~h}$, carbonates had partially decomposed and reacted to form the 2201 phase and after the second calcination step, the $\mathrm{Bi}-2212$ is the major one, coexisting with 
some secondary phases such as $\mathrm{Bi}-2201, \mathrm{CaCuO}_{2}$, and $\mathrm{CuO}$. In sample S2, Bi2212, $\mathrm{Bi}-2201$, and $\mathrm{Ca}_{2} \mathrm{CuO}_{3}$ have been clearly identified after the thermal treatments, while almost pure 2212 phase was found in sample S3. For samples S4, the analysis showed that an amorphous material was formed and, as a consequence, no phase could be identified.

The morphologies of the starting powders, after the annealing processes, have been observed by SEM. Representative micrographs for the final precursors S1, S2, and S3, are shown in Fig. 4. It was found that S1 and S2 (Figs. 4a and 4b) powders are inhomogeneous regarding the grain sizes, they are formed by agglomerates composed, in turn, of very small grains together with big grains. On the other hand, S3 powders have bigger mean size, less agglomerates, and lower grain size dispersion (see Fig. 4c) than S1 and S2.

Finally, the aspect of the fractured final cylinders, obtained by the $S 4$ route, is illustrated with Fig. 5. In the micrograph it is clear that the rupture is that corresponding to a fragile material where it is possible to distinguish the three typical regions (mirror, mist and hackle) [22]. Higher magnification image represented as an insert shows no evidence of grains, confirming the amorphous nature of the precursor observed in the XRD data.

\subsection{Textured materials characterization}

The main superconducting and nonsuperconducting phases developed during the LFZ processing of the four different BSCCO precursors just discussed above, have been identified by powder XRD diffraction. The phases found in the different as-grown samples are the same, independently of the precursor, and associated to $\mathrm{Bi}-2201$ and $\left(\mathrm{Ca}_{1-x} \mathrm{Sr}_{x}\right) \mathrm{CuO}_{2}$. This result is in agreement with the 
fact that Bi-2212 melts incongruently and the solidification process produces several secondary phases. On the other hand, the large and very stable thermal gradient found in the liquid-solid interphase, produced by the laser radiation, allows obtaining well textured and homogeneous samples.

SEM microstructural observations on as-grown materials showed that all the textured rods posses similar phase distribution and morphology. This characteristic is indicating that the melt is chemically similar in all cases, probably as a consequence of the homogeneization produced in the melt. A representative micrograph performed on a longitudinal polished section of the as-grown material obtained from the $\mathrm{S} 1$ precursor is displayed in Fig. 6, where three different phases can be identified. The primary solidification phase is the Bi-free $\left(\mathrm{Ca}_{1-\mathrm{x}} \mathrm{Sr}_{\mathrm{x}}\right) \mathrm{CuO}_{2}$ (dark contrast in the micrographs identified by EDX), independently of the precursor used. This phase appears well aligned with the rod axis, as expected from the flat solidification interface observed in the growth process [23]. Major phase is the light grey one which shows a composition close to the ideal Bi-2201 stoichiometry. This phase's formation is promoted by its fast solidification kinetics from the Bi-enriched liquid, a process which follows initial nucleation of $\left(\mathrm{Ca}_{1-\mathrm{x}} \mathrm{Sr}_{\mathrm{x}}\right) \mathrm{CuO}_{2}$. Moreover, from the trends observed in Fig. 6 it can be deduced that the grain growth of this Bi-rich phase follows the alignment of the primary solidified phase. Small black spots distributed inside the Bi-rich phase have been identified as $\mathrm{CaO}$ particles.

During the two-steps annealing of the as-grown materials, the above phases react between them and almost dissapeared, leading to nearly Bi-2212 single phase textured rods. In the first annealing process, the Bi-2212 formation is produced, following the equilibrium ecuation: 
$\mathrm{Bi}-2201+\left(\mathrm{Ca}_{1-\mathrm{x}} \mathrm{Sr}_{\mathrm{x}}\right) \mathrm{CuO}_{2}+\mathrm{CaO} \leftrightarrow \mathrm{Bi}-2212$

while the second step is designed to adjust the oxygen content in the Bi-2212 phase.

Powder XRD performed on annealed samples showed that Bi-2212 is the major phase, with only small amounts of Bi-2201, in all cases. This is illustrated in Fig. 7, where the XRD plot of the S2 sample is represented. Unmarked peaks correspond to the 2212 phase, while the * indicates the 2201 peaks. This diagram clearly indicates the plate-like geometry of the 2212 grains, as the $(00 \mathrm{I})$ diffraction peaks show higher intensity than the obtained in randomly oriented grains. This effect is only due to the grain geometry which induces a preferential orientation on the sample holder.

The microstructure of these samples is represented in Fig. 8, where a representative longitudinal polished section, corresponding to the S3 sample is shown. EDX analysis of the different contrasts confirm that Bi-2212 is the major phase (gray contrast), accompanied by Bi-2201 (white contrast), as deduced from the XRD data. Moreover, SEM images allow the identification of two minor phases, the black contrast one corresponding to $\mathrm{CaO}$, and the dark gray one to $\left(\mathrm{Ca}_{1-\mathrm{x}} \mathrm{Sr}_{\mathrm{x}}\right) \mathrm{Cu}_{2} \mathrm{O}_{3}$. From the XRD data and the SEM images, it is clear that most of the $\left(\mathrm{Ca}_{1-\mathrm{x}} \mathrm{Sr}_{\mathrm{x}}\right) \mathrm{CuO}_{2}, \mathrm{CaO}$, and 2201 phases have reacted to produce the 2212 phase. The amount of the different phases has been estimated by image analysis using several SEM micrographs of the annealed rods produced with the four different precursors. Mean values for the content of each phase are very similar for all the samples, with about $95 \%$ of $\mathrm{Bi}-2212,1 \%\left(\mathrm{Ca}_{1-\mathrm{x}} \mathrm{Sr}_{\mathrm{x}}\right) \mathrm{Cu}_{2} \mathrm{O}_{3}$, $<1 \% \mathrm{CaO}$, and 3\% Bi-2201. 
The very similar microstructure and phase content observed previously is reflected in the electrical properties, except for the samples obtained from the S3 precursor, as it is illustrated by Fig. 9, where resistivity vs temperature from 77 to $300 \mathrm{~K}$ is represented. From these data, $T_{c}$ values have been determined for each sample with values about $89 \mathrm{~K}$ for the annealed rods prepared with the S1, S2, and S4 precursors, and about 94K for those synthesized with the S3 precursor. This important difference in the $T_{c}$ values has already been evidenced on sintered samples processed under reducing atmosphere [24-26] and it is due to the difference on the $\delta$ values, smaller in the case of samples prepared with the S3 precursor.

The evolution found on the $T_{c}$ values is also maintained on the $J_{c}$ measurements at $77 \mathrm{~K}$ represented in Fig. 10. From these data, $J_{c}$ values were determined using the standard $1 \mu \mathrm{V} / \mathrm{cm}$ criterion. Samples prepared with the S3 precursor have a higher transport capacity (about $3800 \mathrm{~A} / \mathrm{cm}^{2}$ ) than the obtained by the other three methods (about $3300 \mathrm{~A} / \mathrm{cm}^{2}$ ), which represents an increase of $\sim 15 \%$. The difference is explained by the lower $T_{c}$ found on the $S 1$, $\mathrm{S} 2$ and $\mathrm{S} 4$ samples which makes that the $\mathrm{J}_{\mathrm{c}}$ measurements (at $77 \mathrm{~K}$ ) are performed at temperatures closer to their $\mathrm{T}_{\mathrm{c}}$ (around $89 \mathrm{~K}$ ) than for the $\mathrm{S} 3$ samples (around 94K).

On the other hand, when transport properties are determined at lower temperatures, the differences on $J_{c}$ for the different samples become nearly negligible, as illustrated in Fig. 11, where $J_{c}$ values vs temperature are represented between 78 and $72 \mathrm{~K}$. Lower temperatures until $\sim 65 \mathrm{~K}$ could not be used to determine $J_{c}$ due to the high increase of the transport properties with 
the decrease of temperature, reaching the intensity source higher limit (about 250 A).

\section{CONCLUSIONS}

$\mathrm{Bi}-2212$ textured rods have successfully been fabricated from four different types of precursors. The results indicate that the annealed textured rods microstructure is not affected by the phase content and morphology of the starting powder grains.

The high $\mathrm{T}_{\mathrm{c}}$ obtained in textured materials obtained from the $\mathrm{S} 3$ precursor are assigned to the lower oxygen content found in these samples. This raise in $T_{c}$ leads to an increase on the $J_{c}$ values at $77 \mathrm{~K}$ (about $15 \%$ ), while at lower temperatures the $J_{c}$ difference between the different samples turns negligible. These differences are of enough importance to use materials obtained from the S3 precursors when the application would be performed at 77K, while at lower temperatures the $S 4$ precursor would be chosen due to its simplicity and quick conformation.

\section{Acknowledgements}

The authors wish to thank the Gobierno de Aragón (Research Groups T12 and T72, and project PI154/08), and the Spanish Ministry of Science and Innovation (Project MAT2008-00429) for financial support. The technical contributions of C. Estepa, J. A. Gómez and C. Gallego are also acknowledged.

\section{References}


1. M. Chen, L. Donzel, M. Lakner, and W. Paul, J. Eur. Ceram. Soc. 24, 1815 (2004).

2. P. F. Hermann, Handbook of Applied Superconductivity (IOP Publishing, Bristol, 1998).

3. M. Noe, K. P. Juengst, F. N. Werfel, S. Elschner, J. Bock, F. Breuer, and R. Kreutz, IEEE Trans. Appl. Supercond. 13, 1976 (2003).

4. V. Garnier, R. Caillard, A. Sotelo, and G. Desgardin, Physica C 319, 197 (1999).

5. H. Maeda, K. Ohya, M. Sato, W. P. Chen, K. Watanabe, M. Motokawa, A. Matsumoto, H. Kumakura, and J. Schwartz, Physica C 382, 33 (2002).

6. M. S. Martin-Gonzalez, J. Garcia-Jaca, E. Moran, and M. A. Alario-Franco, J. Mater. Res. 14, 3497 (1999).

7. R. S. Feigelson, D. Gazit, D. K. Fork, and T. H. Geballe, Science 240, 1642 (1988).

8. A. Sotelo, M. Mora, M. A. Madre, J.C. Diez, L. A. Angurel, and G. F. De la Fuente, J. Eur. Ceram. Soc. 25, 2947 (2005).

9. M. Mora, A. Sotelo, H. Amaveda, M. A. Madre, J. C. Diez, F. Capel, and J. M. López-Cepero, J. Eur. Ceram. Soc. 27, 3959 (2007).

10. G. F. de la Fuente, M. T. Ruiz, A. Sotelo, A. Larrea, and R. Navarro, Mat Sci. Eng. A 173, 201 (1993).

11. D. Shi, High Temperature Superconducting Materials Science and Engineering (Pergamon Press, Oxford, 1995).

12. M. T. Ruiz, G. F. de la Fuente, A. Badia, J. Blasco, M. Castro, A. Sotelo, A. Larrea, F. Lera, C. Rillo, and R. Navarro, J. Mater. Res. 8, 1268 (1997). 
13. A. Sotelo, P. Majewski, H.-S. Park, and F. Aldinger, Physica C 272, 115 (1996).

14. M. F. Carrasco, F. M. Costa, R. F. Silva, F. Gimeno, A. Sotelo, M. Mora, J.

C. Diez, and L. A. Angurel, Physica C 415, 163 (2004).

15. R. Roy, Science 238, 1664 (1987).

16. G. F. de la Fuente, A. Sotelo, Y. Huang, M. T. Ruiz, A. Badia, L. A. Angurel,

F. Lera, R. Navarro, C. Rillo, R. Ibañez, D. Beltran, F. Sapiña, and A. Beltran, Physica C 185-189, 509 (1991).

17. A. Sotelo, H. Szillat, P. Majewski, and F. Aldinger, Supercond. Sci. Technol. 10, 717 (1997).

18. R. Funahashi, I. Matsubara, K. Ueno, and H. Ishikawa, Physica C 311, 107 (1999).

19. M. Mora, E. Martinez, J. C. Diez, L. A. Angurel, and G. F. de la Fuente, J. Mater. Res. 15, 614 (2000).

20. M. Mora, J. Fernández, L. A. Angurel, and R. Navarro, Physica C 312, 136 (1999).

21. G. Desgardin, M. P. Delamare, F. Delorme, V. Garnier, F. Giovannelli, C. Leblond-Harnois, S. Marinel, I. Monot-Laffez, V. Rouessac, and J. Wang, Intl. J. Inorg. Mater. 2, 609 (2000).

22. D. Hull, Fractography: observing, measuring and interpreting fracture surface topography (Cambridge University Press; Cambridge, 1999).

23. G. F. de la Fuente, J. C. Diez, L. A. Angurel, J. I. Peña, A. Sotelo, and R. Navarro, Adv. Mater. 7, 853 (1995).

24. N. Fukushima, H. Niu, S. Nakamura, S. Takano, M. Hayashi, and K. Ando, Physica C 159, 777 (1989). 
25. S. K. Agarwal, V. P. S. Awana, V. N. Moorthy, P. Maruthi Kumar, B. V.

Kumaraswamy, C. V. Narashima Rao, and A. V. Narlikar, Physica C 160, 278 (1989).

26. A. Sotelo, J. I. Peña, L. A. Angurel, J. C. Diez, M. T. Ruiz, G. F. de la Fuente, and R. Navarro, J. Mater. Sci. 32, 5679 (1997). 
Table I

\begin{tabular}{|c|c|c|c|}
\hline & Starting mixture & $750^{\circ} \mathrm{C} 12 \mathrm{~h}$ & $800^{\circ} \mathrm{C} 12 \mathrm{~h}$ \\
\hline Solid state & $\begin{array}{l}\mathrm{Bi}_{2} \mathrm{O}_{3} \\
\mathrm{SrCO}_{3} \\
\mathrm{CaCO}_{3} \\
\mathrm{CuO}\end{array}$ & $\begin{array}{l}\mathrm{Bi}-2201^{\mathrm{b}} \\
\mathrm{CaCuO}{ }_{2} \\
\mathrm{CuO}\end{array}$ & $\begin{array}{l}\mathrm{Bi}-2212^{\mathrm{b}} \\
\mathrm{Bi} 2201 \\
\mathrm{CaCuO}_{2} \\
\mathrm{CuO}\end{array}$ \\
\hline Sol-gel & $\begin{array}{l}{\mathrm{Bi}-2201^{\mathrm{a}}} \mathrm{CaCO}_{3} \\
\mathrm{CuO} \\
\mathrm{CaCu}_{2} \mathrm{O}_{3}\end{array}$ & $\begin{array}{l}\mathrm{Bi}-2212^{\mathrm{a}} \\
\mathrm{Bi}-2201^{\mathrm{b}} \\
\mathrm{CaCu}_{2} \mathrm{O}_{3} \\
\mathrm{CuO}\end{array}$ & $\begin{array}{l}\mathrm{Bi}-2212^{\mathrm{b}} \\
\mathrm{Bi} 2201 \\
\mathrm{CaCu}_{2} \mathrm{O}_{3} \\
(\mathrm{Sr}, \mathrm{Ca}) \mathrm{CuO}_{2}\end{array}$ \\
\hline Polymer & $\begin{array}{l}\mathrm{Bi}-2201^{\mathrm{a}} \\
\mathrm{CaCO}_{3} \\
\mathrm{CuO} \\
\mathrm{Ca}_{2} \mathrm{CuO}_{3}\end{array}$ & $\begin{array}{l}\mathrm{Bi}-2212^{\mathrm{a}} \\
\mathrm{Bi}-2201^{\mathrm{b}} \\
\mathrm{Ca}_{2} \mathrm{CuO}_{3} \\
\mathrm{CuO}\end{array}$ & $\begin{array}{l}\mathrm{Bi}-2212^{\mathrm{b}} \\
\mathrm{Bi} 2201^{\mathrm{a}} \\
\mathrm{Ca}_{2} \mathrm{CuO}_{3}{ }^{\mathrm{a}}\end{array}$ \\
\hline
\end{tabular}




\section{Figure captions}

Figure 1. Schematic representation of the melt quenching system used to prepare vitreous cylindrical precursors.

Figure 2. Vitreous cylindrical precursors after extraction from the quartz tubes.

Figure 3. Evolution of the particle size vs treatment time for the powders obtained by the different sinthetic methods. $\bullet \mathrm{S} 1 ; \bullet \mathrm{S} 2$; and $\boldsymbol{\mathrm { S }} 3$.

Figure 4. SEM micrographs of the final powders obtained by the different synthetic methods: a) S1, b) S2, and c) S3.

Figure 5. SEM micrograph of the fractured cylinder obtained with the S4 precursor. The insert, at higher magnification, shows no evidence of crystals in the bulk material.

Figure 6. SEM micrograph of a longitudinal polished section performed on the as-grown textured rods obtained with the $\mathrm{S} 1$ precursor. $\left(\mathrm{Ca}_{1-\mathrm{x}} \mathrm{Sr}_{\mathrm{x}}\right) \mathrm{CuO}_{2}$, observed as elongated dark grains, is the primary crystallization phase. Major gray contrast is associated to the $\mathrm{Bi}-2201$ phase while small black spots are identified as $\mathrm{CaO}$. 
Figure 7. Typical powder XRD plot of an annealed textured rod, in this case it has been prepared with the S2 precursor. Unmarked peaks correspond to the Bi-2212 phase, while * indicates the Bi-2201 phase peaks.

Figure 8. SEM micrograph of a longitudinal polished section performed on the annealed textured rods obtained with the S2 precursor. Dark gray contrast corresponds to the major phase (Bi-2212), accompained by Bi-2201 phase (white contrast) and small black spots $(\mathrm{CaO})$.

Figure 9. Resistivity measurements vs. temperature, for textured samples after annealing, as a function of the synthetic method. $\bullet \mathrm{S} 1 ; \bullet \mathrm{S} 2 ; \mathbf{S} 3$; and $\nabla \mathrm{S} 4$.

Figure 10. J measurements vs. electrical field at $77 \mathrm{~K}$, for textured samples after annealing, as a function of the synthetic method. $\bullet \mathrm{S} 1 ; \bullet \mathrm{S} 2 ; \boldsymbol{\mathrm { S }} 3$; and $\boldsymbol{\nabla} \mathrm{S} 4$.

Figure 11. $\mathrm{J}_{\mathrm{c}}$ measurements vs. temperature, for textured samples after annealing, as a function of the synthetic method. $\bullet$ S1; $\checkmark \mathrm{S} 2 ; \mathbf{S} 3$; and $\nabla$ S4. 
Figure 1
Click here to download high resolution image

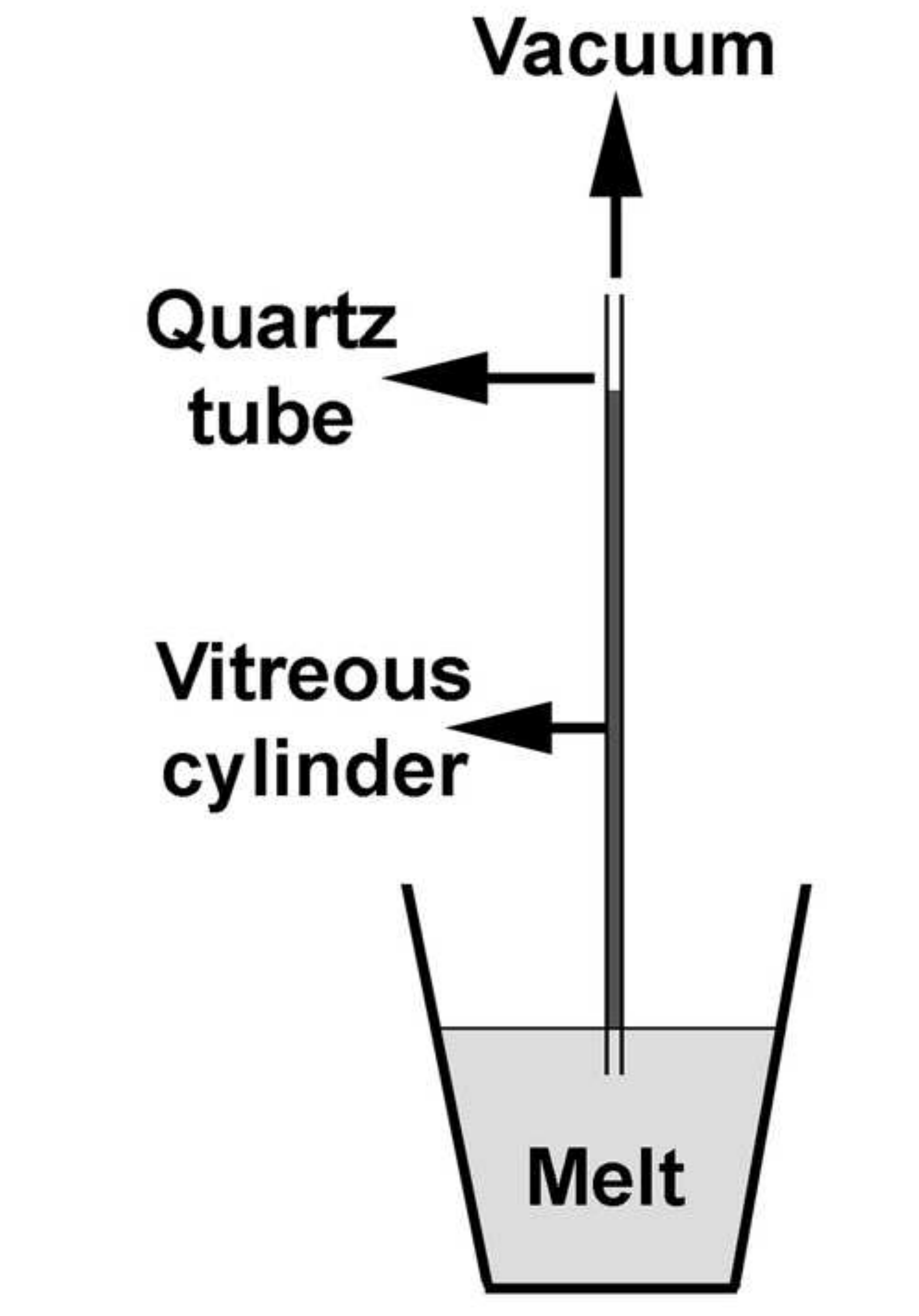

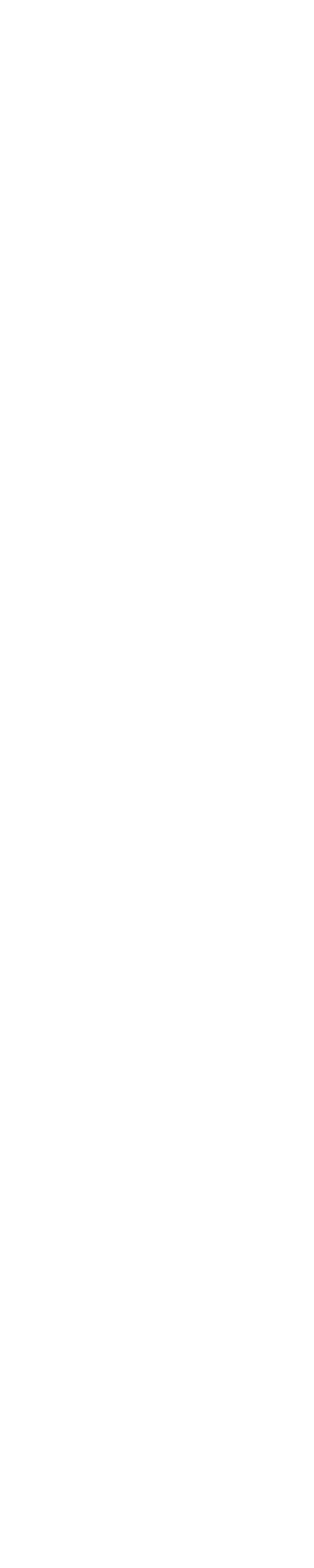


Click here to download high resolution image

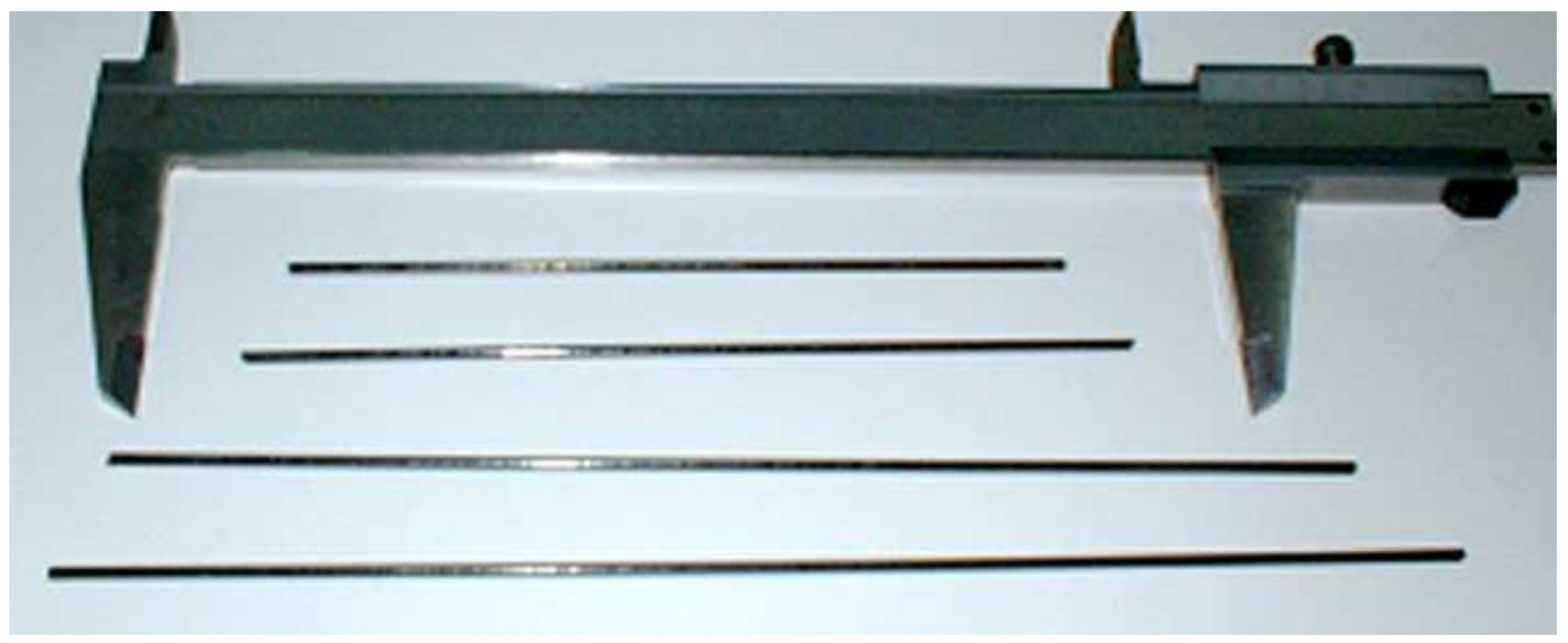




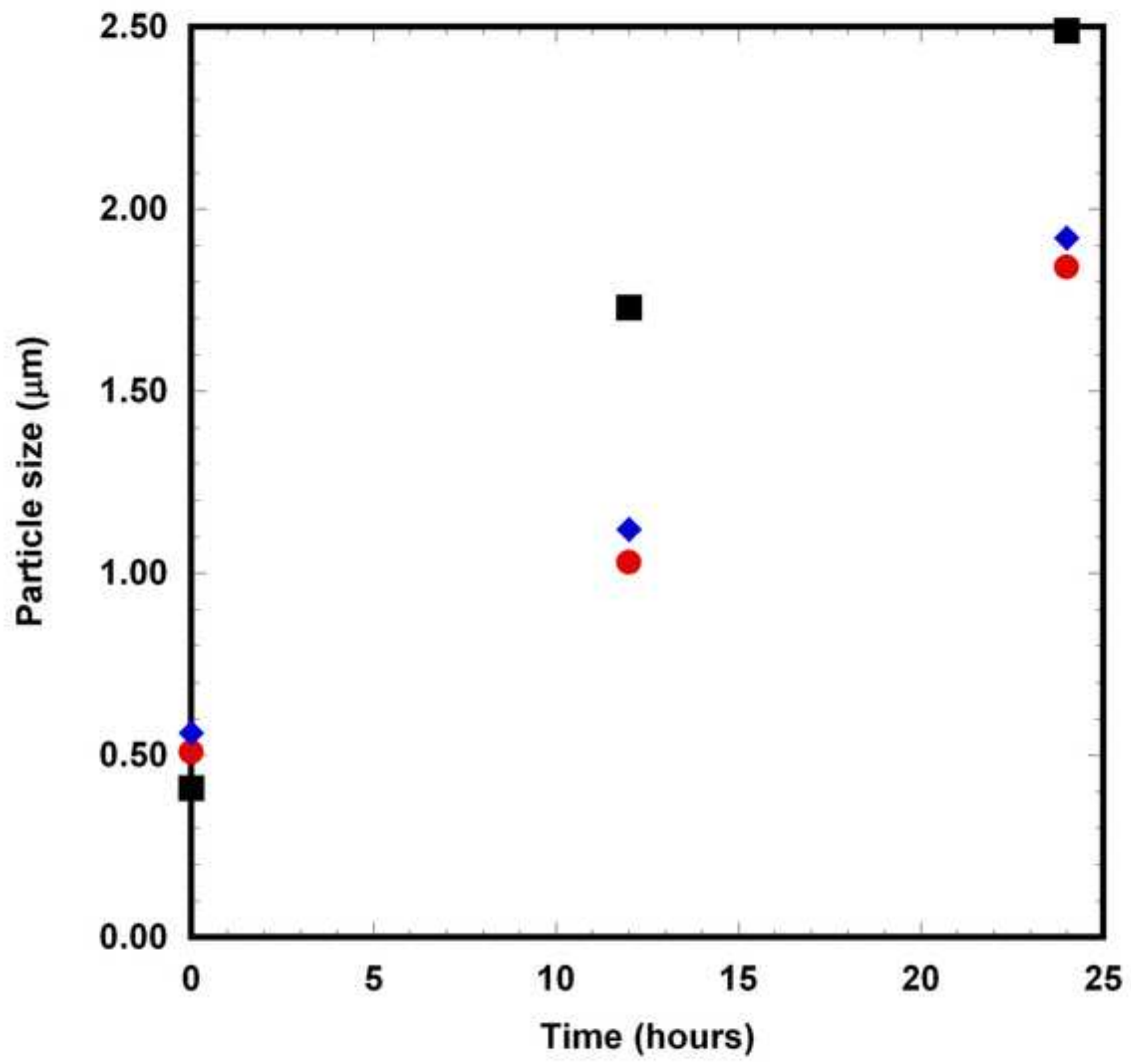


Click here to download high resolution image
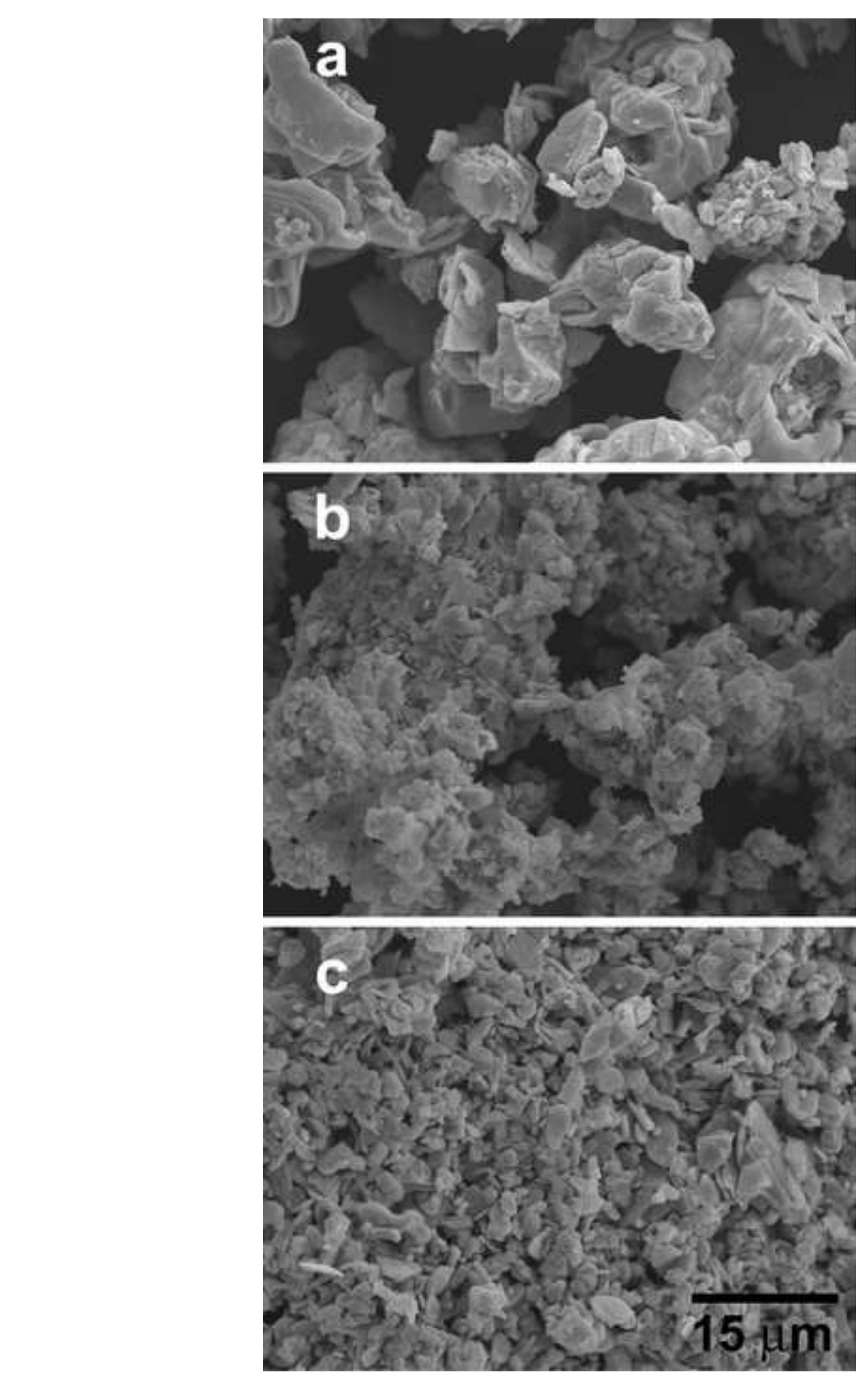

Figure 4

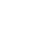

\section{. \\ .}

\section{.}


Click here to download high resolution image

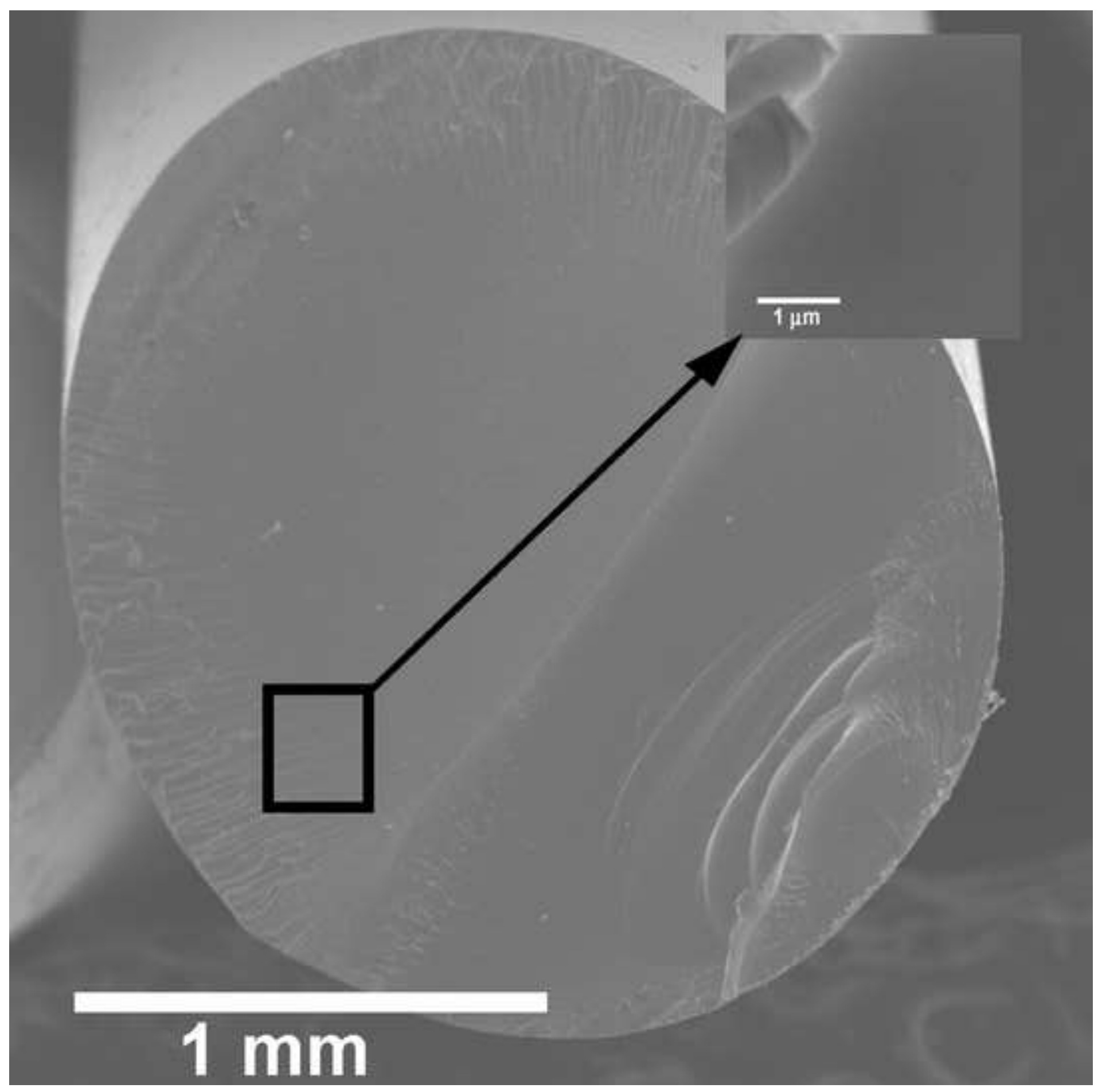


Click here to download high resolution image

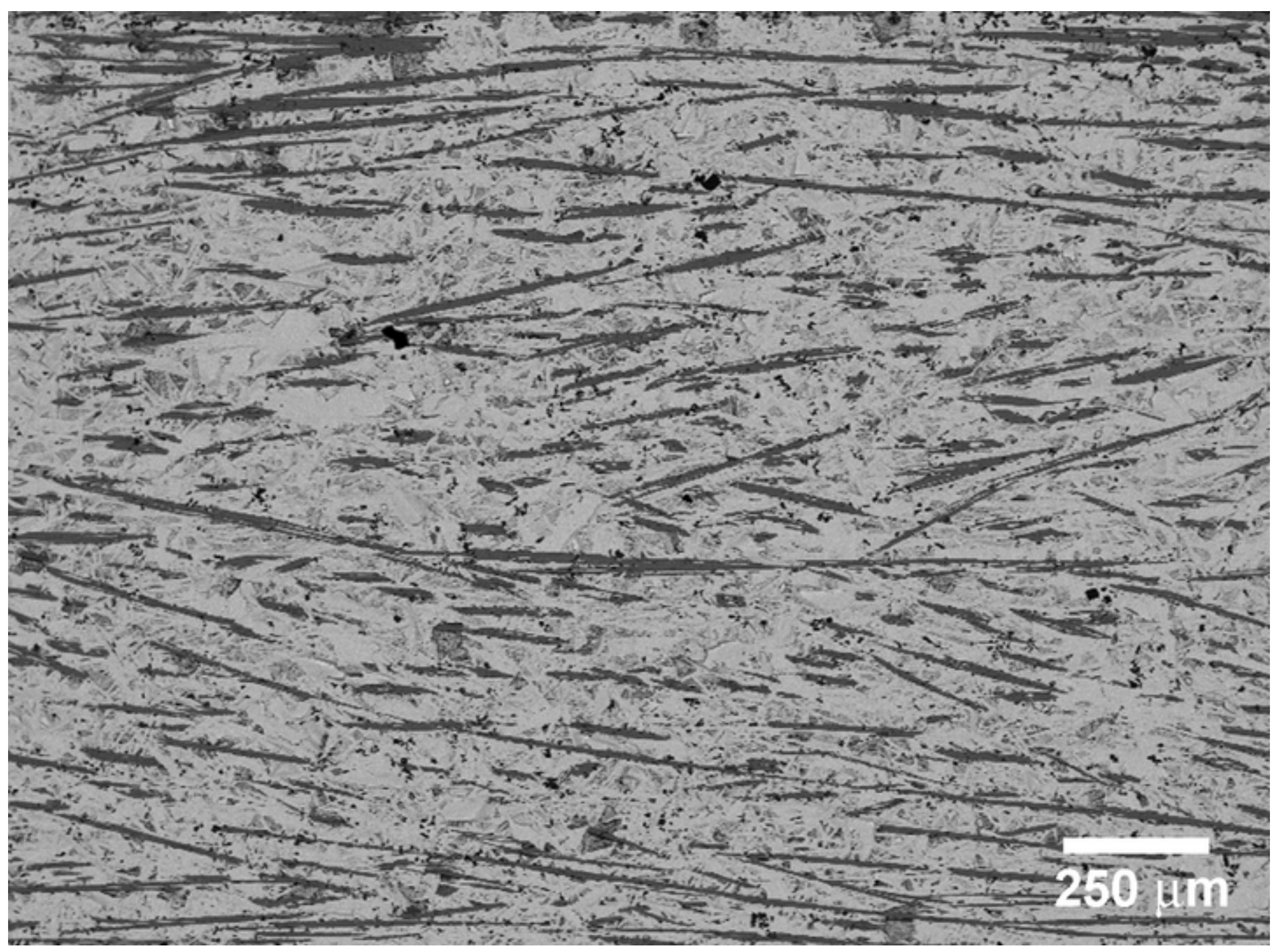




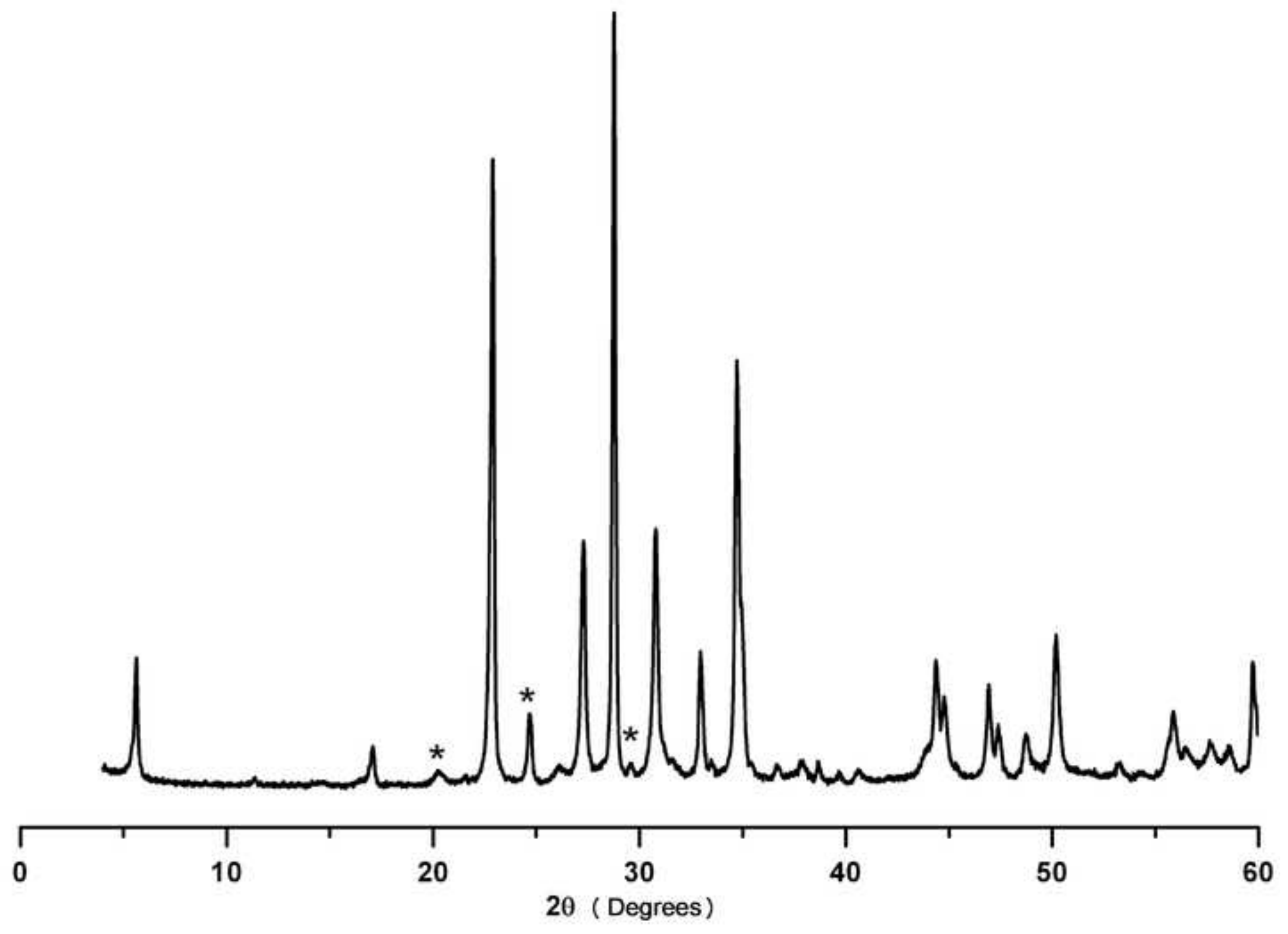




\section{Figure}

Click here to download high resolution image

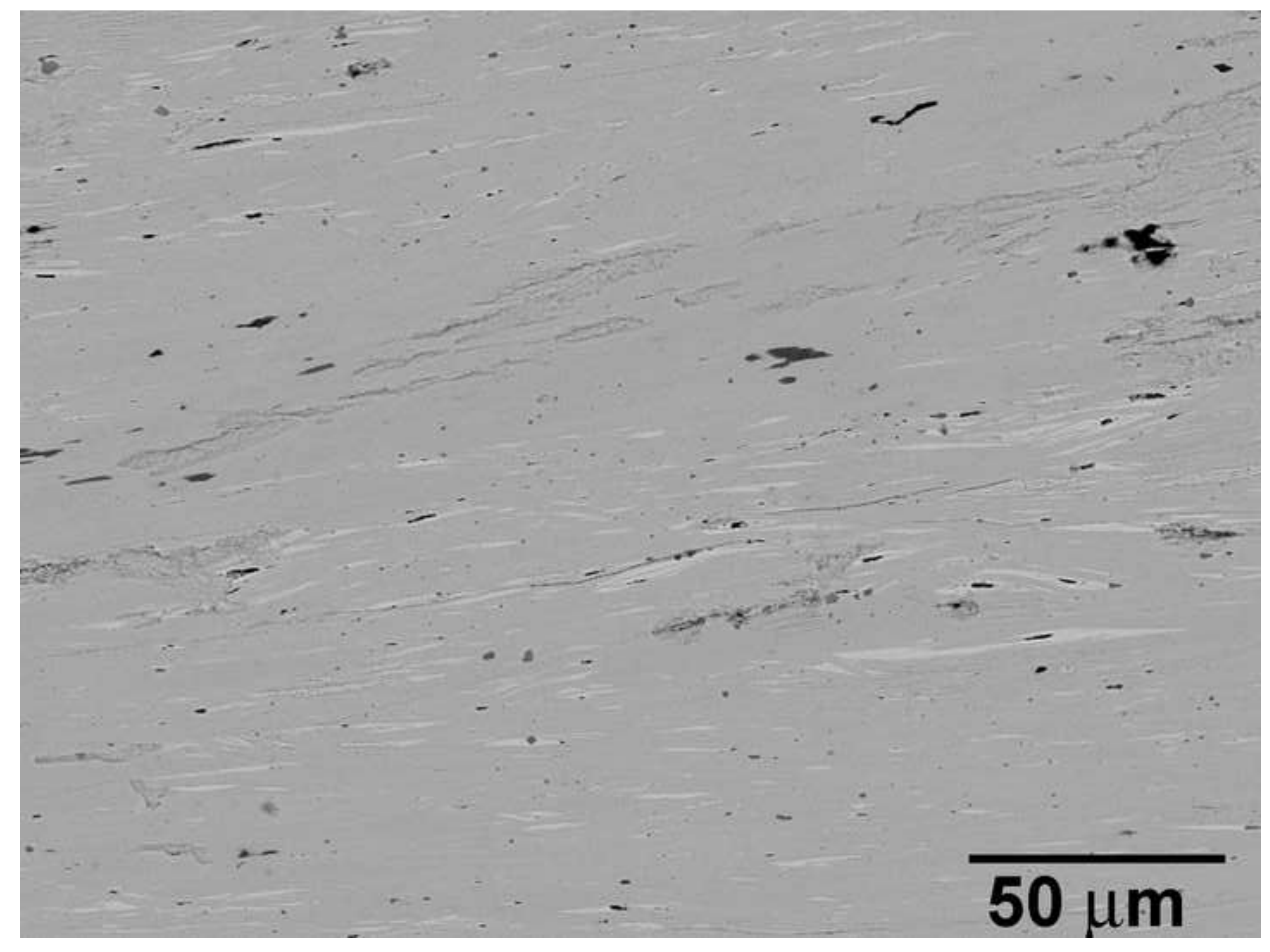


Click here to download high resolution image

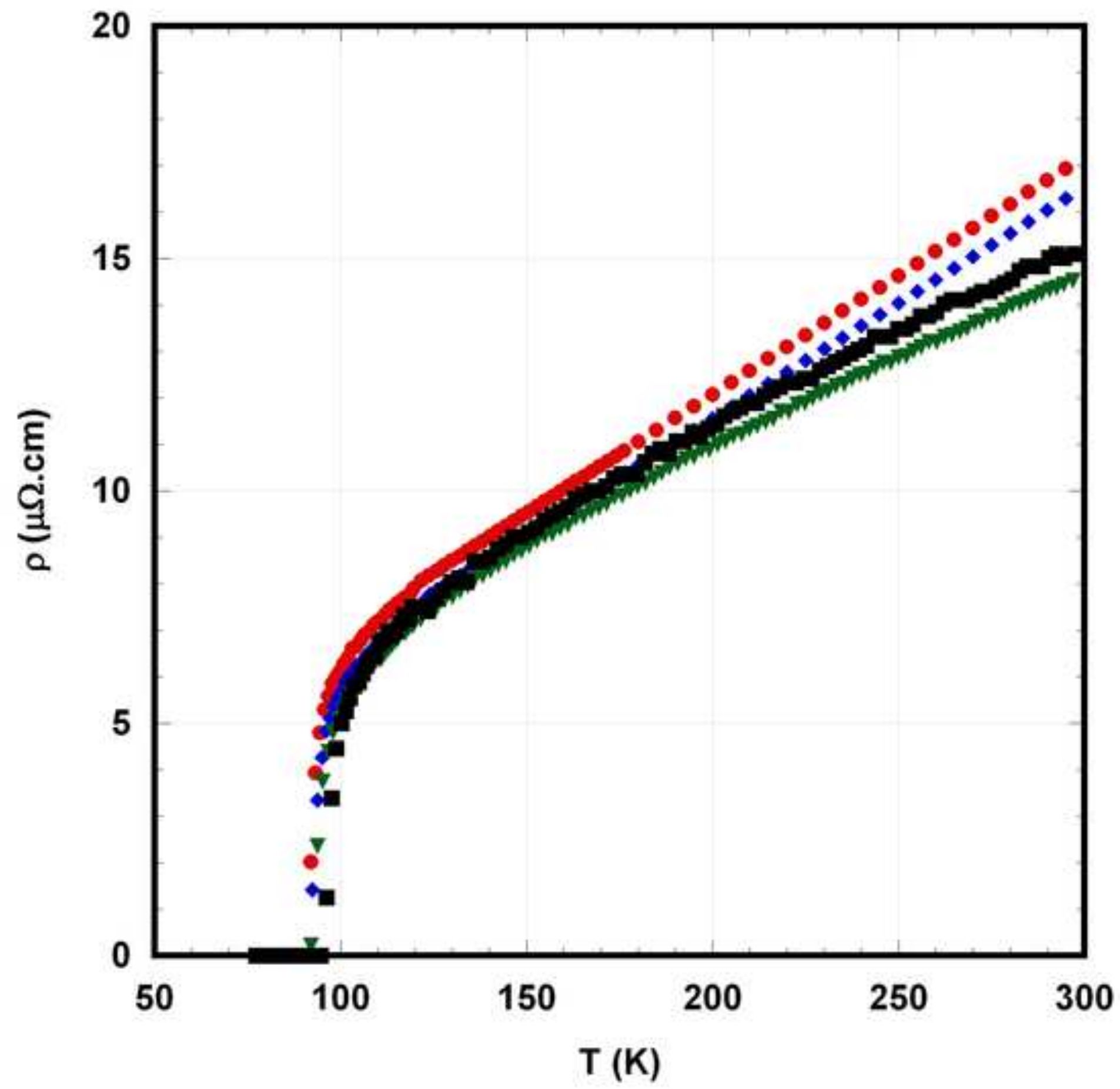




\section{Figure 10}

Click here to download high resolution image

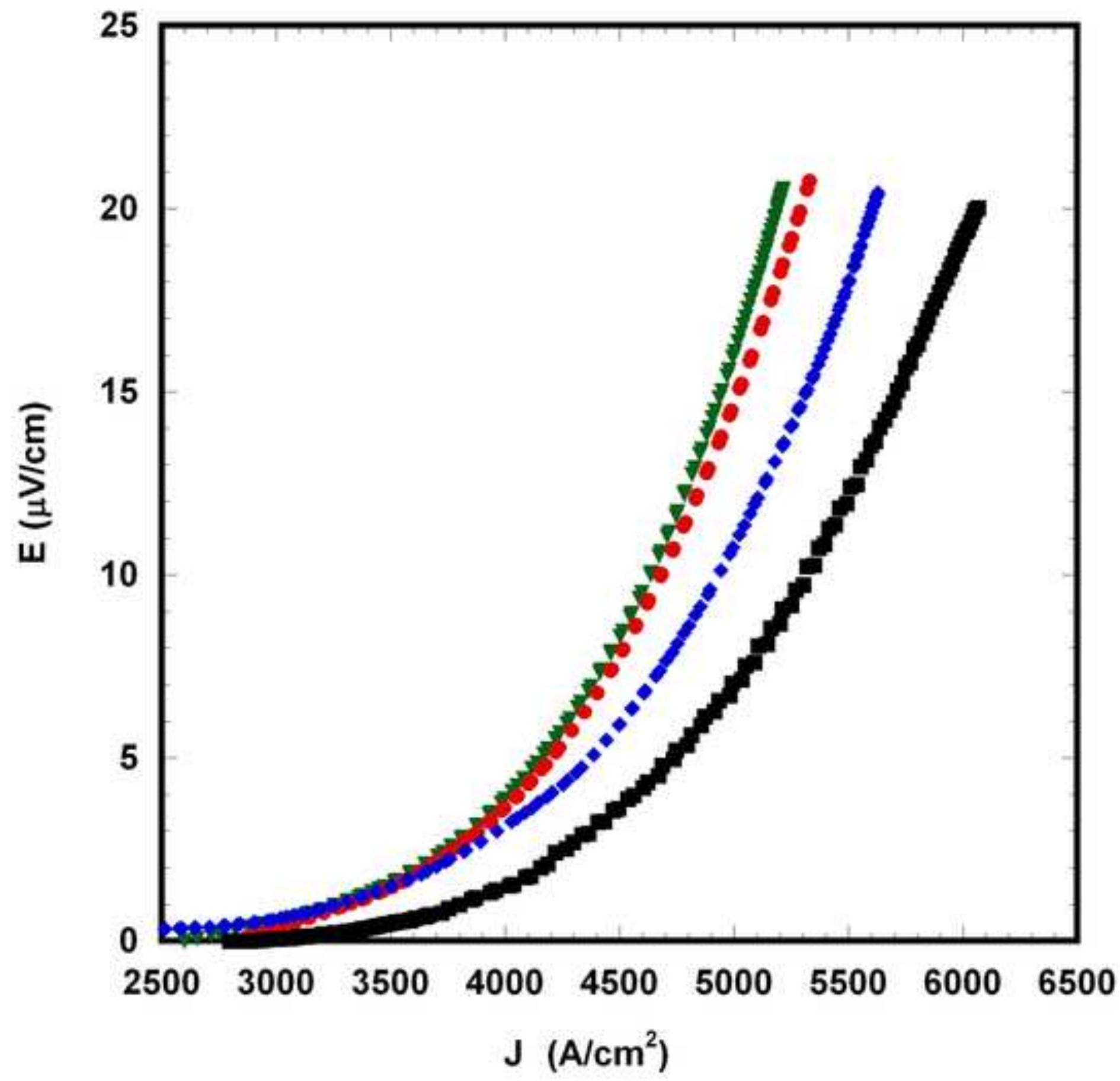


Click here to download high resolution image

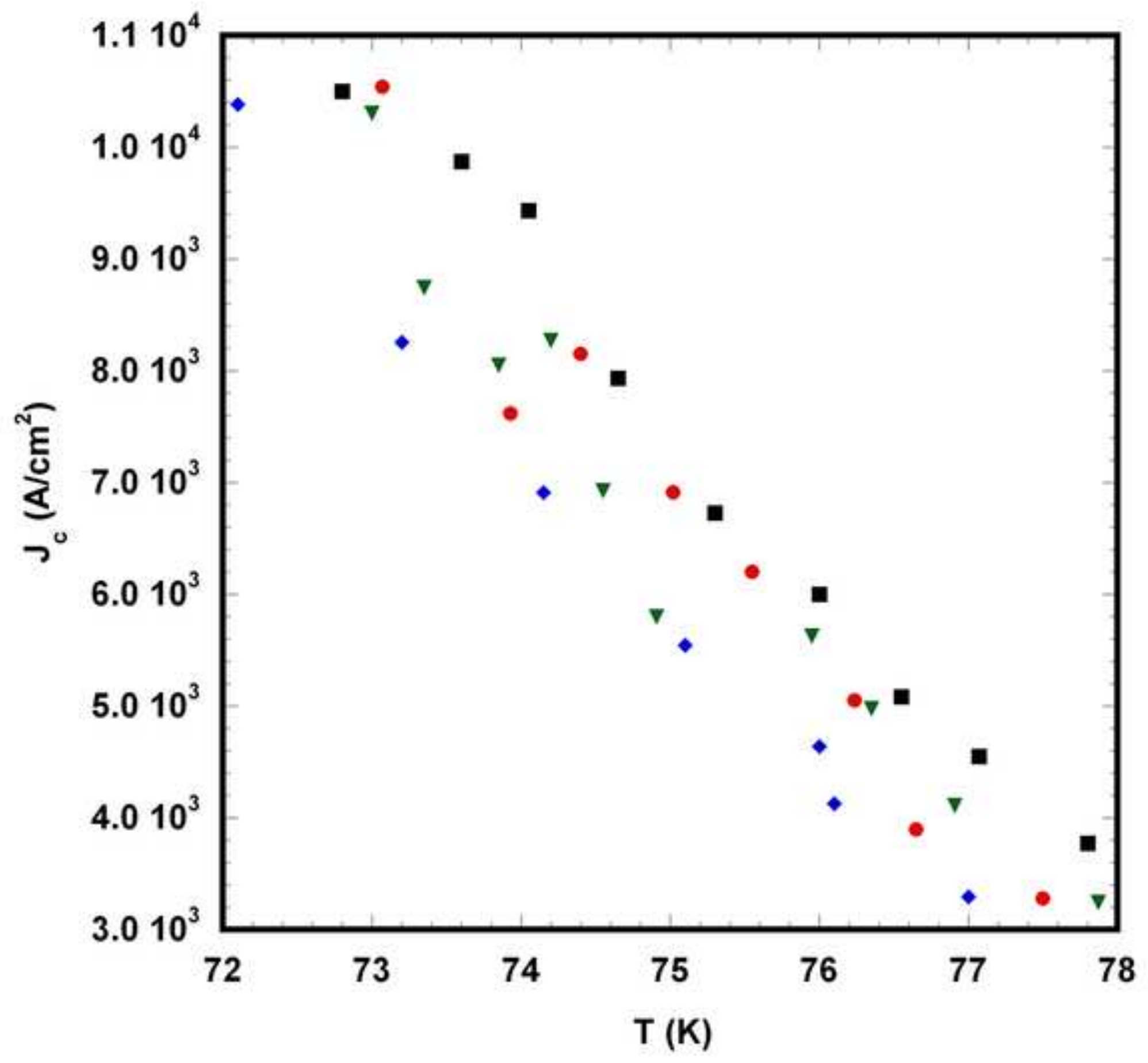

